\title{
Platform Business in Korea: Advent and Growth of Kakao
}

\author{
Yoo-Jin $\operatorname{Han}^{1, *}$ \\ ${ }^{1}$ Department of Entrepreneurship, School of Global Service, Sookmyung Women's University, \\ Cheongpa-ro 47-gil 100, Yongsan-gu, Seoul, Korea, 04310
}

\begin{abstract}
With the rapid development of ICT technology, a platform business is exerting a dominant influence in various fields. This type of a business has a great ripple effect in that it creates value by engaging and connecting various market actors such as producers, suppliers, and business partners to the platform ecosystem, rather than directly selling independent products or services. In this vein, the current study introduces the emergence and growth process of Kakao, which has a monopolistic dominance in the Korean mobile messenger market, as an example of a platform business. This company started to be distributed to Korean consumers in 2010 and is currently exercising its market influence in various fields such as commerce, entertainment, finance, and transportation, and more growth is expected in the future. Based on the case investigation, the background of Kakao's success can be interpreted with a combination of various reasons, such as Korea's developed ICT environment, a large game users' population, quick service launch, the strategy to utilize the founder's previous work experience, and service development geared towards Korean consumers.
\end{abstract}

Keywords: ICT, platform, Kakao, growth

\section{Introduction}

In recent years, platform business strategies have gained massive interests not only in the academic fields but in the practical aspects[1-5]. In this "Big Wave" era, Kakao Talk has become a national communication channel in Korea since its emergence in 2010[6]. Within this 11 year period, it became a representative company and expanded its business encompassing entertainment, finance, and transportation. In recent years, the number of Kakao's subsidiaries reached 118, following one of Korea's largest business groups, i.e., SK. In terms of market capitalization, it ranked 3rd, followed by Naver, which has been dominating the Korean Internet market since the late 1990s.

This company has positioned itself as a leader in Korea's mobile ecosystem by entering various areas, such as artificial intelligence, big data, internet of things, blockchain, and so on. It actively participates in technology development in the era of the 4th Industrial Revolution and maintains the leading position.

${ }^{*}$ Corresponding author: yjhan $@$ sookmyung.ac.kr 
As Kakao's business area has become deeply established in the daily lives of many people, related research to investigate its strategies and impacts has been conducted in various ways. The existing research with respect to Kakao shows the analysis of the growth process of Kakao Talk, motivation, and intention for continuous use, SNS mobile marketing services, the quality of mobile messenger interface design, and platform business and M\&A strategies. In particular, it epitomizes effective platform business strategies in the era of the fastestchanging ICT envoronment.

Preliminary studies analyzed Kakao Talk, related services, platforms, M\&A, and strategies from various perspectives. However, research on Kakao's overall entrepreneurial growth process remains scant. Thus, this study examines the entire process from the start-up to the present and takes three stages into consideration. In addition, the environmental characteristics of the Korean market that acted as the background of Kakao's success must be analyzed to derive implications.

\section{Advent of Kakao}

Kakao's chairman, Bum-soo Kim, joined Samsung SDS in 1992 after obtaining his aster's Degree in Industrial Engineering at the Seoul National University. The company was responsible for the development and operation of PC telecommunications service called " Unitel." In this process, he realized that the Internet era would change the business environment, which led him to quit a stable job in 1998. Then, he established an Internetbased computer game company called "Hangame" in early 1999 and attracted three million members in five months. The first-mover advantages, including technological leadership, preoccupation of scarce resources, and less consumer conversion costs were achieved (Lieberman and Montgomery, 1988). Soon, the number of subscribers reached 10 million owing to the Internet boom.

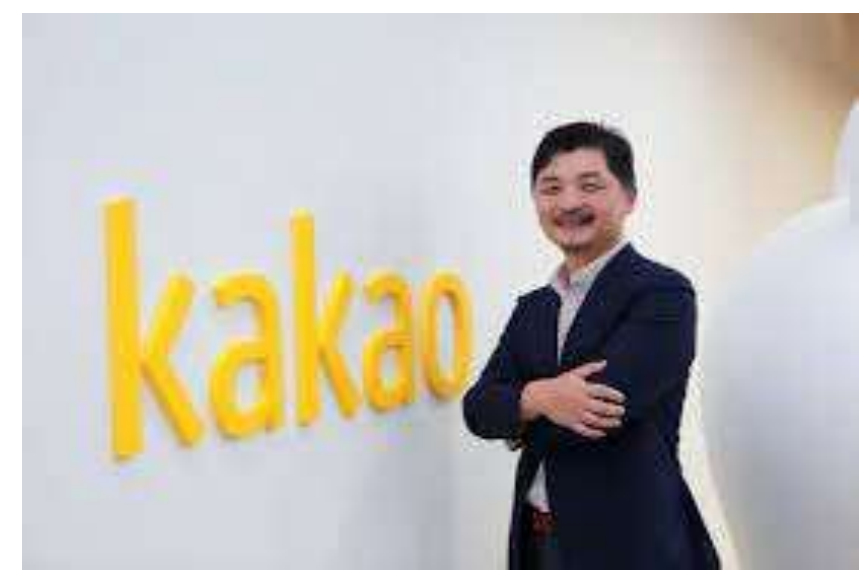

Fig. 1. Bum-soo Kim: Founder \& Chairman of Kakao

Source: K.E. Lee, S.W. Jung, Bum-soo Kim, Kakao founder, handed out his shares to his family and relatives, Chosun Ilbo, Jan. 19 (2021)

The company has grown rapidly since. Meanwhile, Navercom, provided an Internet search engine with a limited number of users by spinning itself off from Samsung SDS. To overcome the limitations of each company, Chairman Bum-soo Kim and Chairman Hae-jin Lee merged Hangame and NaverCom in July 2000. Then the company changed its name to NHN in September 2001. NHN initially generated revenues from the sale of game items, and it started to gain popularity among Korean users through JiSikIn, which is a knowledge 
exchange service embedded in the Naver portal. Later, it became the No.1 portal company in Korea as it started to earn profits from keyword-based search advertisements.

As the major revenue source for Naver changed to these areas, the roles of Chairman Bum-soo Kim have been reduced, which compelled him to quit and start a new business. After moving to USA, he launched various social network services, such as "Buru.com" and "Wisia.com," which eventually failed. In this era, Apple successfully launched its first smartphone in 2008, which influenced him to switch his business to a $100 \%$ mobile-based one. Figure 1 shows the main log-in screen of Kakao Talk.

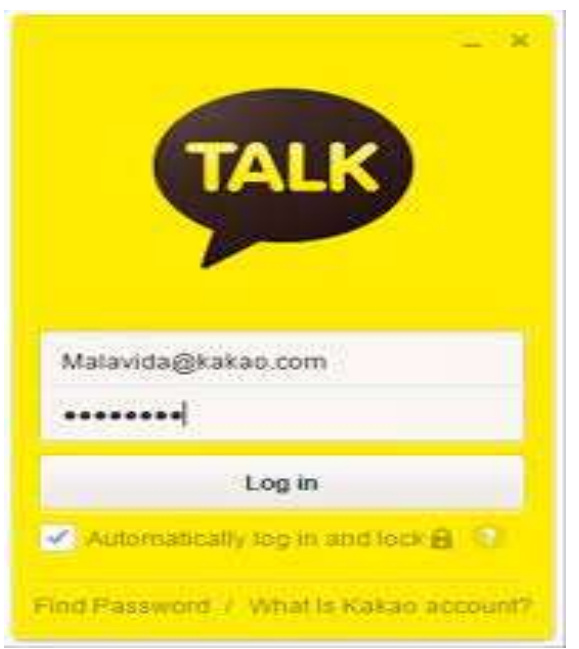

Fig. 2. Log-in screen of Kakao Talk

Source: www.malavia.com

Kakao initiated its business by providing a free platform, which is similar to Hangame. This strategy is highly similar to Google, which provided a search engine for free for two years after its inception to engage advertisers. Facebook also secured enough subscribers for two years through the same strategy. For the two years, 2010 and 2011, Kakao spent 15 million dollars (15 billion Korean won). However, it did not earn any revenues. To strengthen competitiveness in the domestic market and enter the global market, a domestic game company, Wemade, invested 92 million dollars (92 billion Korean won) in 2012. However, the revenue model remained unclear.

With the release of "Playing Kakao Games" in July 2012, the situation began to improve. By forming strategic alliances with seven partner companies and 10 games, including Anipang have been released. At that time, social games were considered a successful business model for overseas companies, such as Facebook and MySpace. In this game space, exiting users invited their friends on the basis of offline relationships. Anipang was a simple mobile game in which people were able to establish relationships with one another by sending invitations, which is represented through a "Heart" emoji. Through this, Kakao successfully influenced middle-aged consumer groups to be interested in using a "new" device called "smartphone." In 2012, Anipang was able to generate 10 million won (10 billion won) in sales. The revenue allocation principle of the App Store:KakaoTalk:developers = 30:21:49 resulted in a 2.1 billion revenue. To secure subscribers, it is often forced to use the Kakao platform, which brought market dominance to Kakao.

With the "free installation policy" and "relationship-based invitation", the number of users reached 45 million as of 2012, which is $90 \%$ of the entire population in Korea as shown in Figure 3. It was part of a platform envelopment strategy[7-8] that extends the scope of the 
usage to other areas on the basis of power[9-13], and it caused a lock-in phenomenon that cannot escape from Kakao Talk.

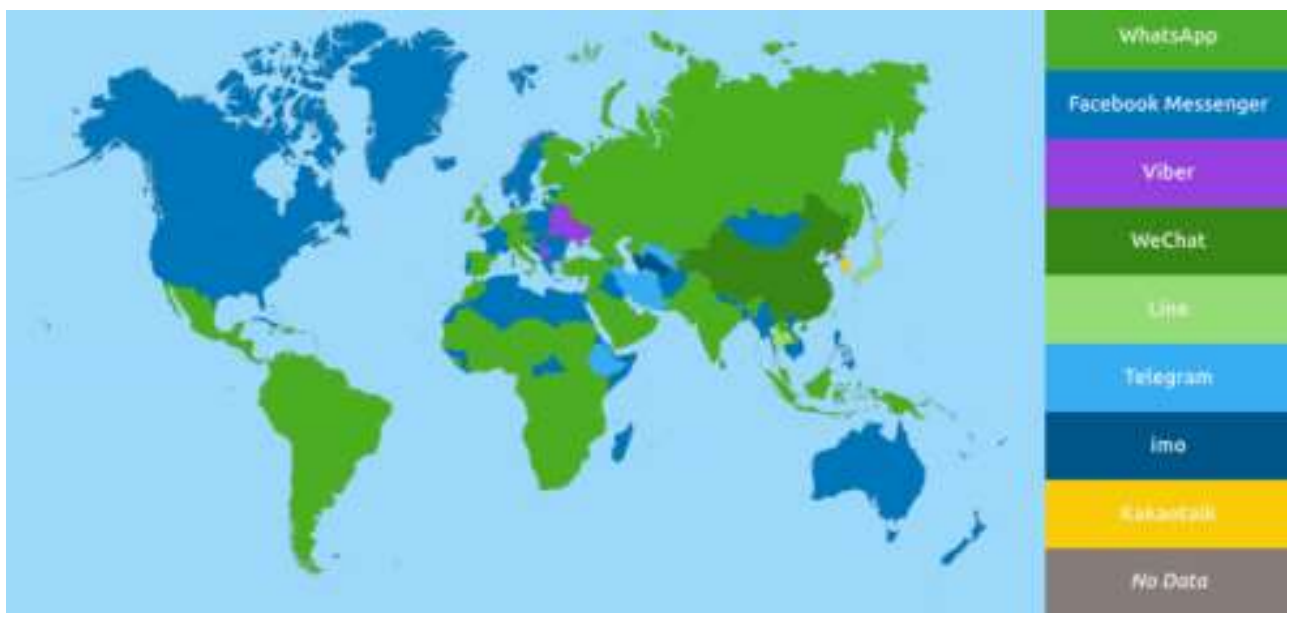

Fig. 3. Market dominance of mobile messenger platforms worldwide

Source: www.messengerpeople.com

\section{Growth of Kakao}

In May 2014, it was merged with a web portal, Daum Communications, and changed the company name to Daum Kakao. The merger is at a rate of 1(Kakao):1.556(Daum), given that the mobile market is expected to grow faster in the future. Then, the company began to provide global services in 15 languages in 230 countries by reinforcing itself.

Kakao's "fast-follower" strategy, which quickly pursued the Facebook's WhatsApp, was driven by Chairman Kim Bum-soo's quick decision making after the failure of Buru.com and Wisia.com. The background of Kakao's fast-follower strategy can also be found in Naver's case.

As a revenue source, first, Kakao Games was spun off, which was a big stepping stone for growth. Concurrently, with the establishment of Oh, K-Cube Ventures, which was established to invest in promising startups, was incorporated into an affiliate. Later, it was reorganized into a holding company (KCUBE Holdings) and a venture capital company (Kakao Ventures). Kakao Investment focuses on start-ups larger than Kakao Ventures investments. Similar to Kim, Kakao Investment will take over a company where businesses are based to a certain extent. It looks organized into The companies that Kakao Ventures invested in are the American augmented reality startups. Other than this effort, Kakao Pay, Kakao Commerce, and Kakao Mobility were established.

To promote the music industry, Loen and Entertainment, which used to run Melon, was incorporated into Kakao M. Recently, by acquiring numerous music-related software developers and entertainment agencies, the company is integrated. the company is expanding into an entertainment company.

Kakao started with "Seoul Bus," a bus arrival information app, after the merger with Daum Communications. It acquired (6.67 billion won), K-Cube Ventures (5.55 billion won), Cellit and a Global Positioning System (GPS) app in May 2015. It acquired Rock and All, which is known as an application called "Kim Gisa," for \$62.6 million (62.6 billion won) and Path, Indonesia's top three social networking websites $\$ 26.3$ million (26.3 billion won). 
Kakao's M\&A strategy peaked in 2016. On January 11, Kakao announced its acquisition of Loen Entertainment, which was famous for its music platform, Melon. The acquisition amounted to $\$ 1.8 \mathrm{~B}$ (1.8743 trillion won), which was extremely exceptional. This was surprising considering that Daum Communications was only worth 100 billion won when it acquired Lycos. The acquisition of Loen, which Kakao announced, aimed to "secure growth engines for mobile content platforms and strengthen competitiveness." Many reasons exist for this merger. First, Kakao could enjoy many advantages, such as adding Kakao Pay as a payment method for Melon, selling music on Kakao Page, and providing exclusive contents of Loen Entertainment artists on Kakao TV. Second, Kakao attempted to lower the dependency on gaming by diversifying revenue sources to Loen, which constantly generated $\$ 60$ million (60 billion Korean won) of sales yearly. Last, Loen utilized K-pop music to enter the global market, which was a good choice to leap to the platform. Figure 4 shows the snapshot of Kakao's diversified business areas.

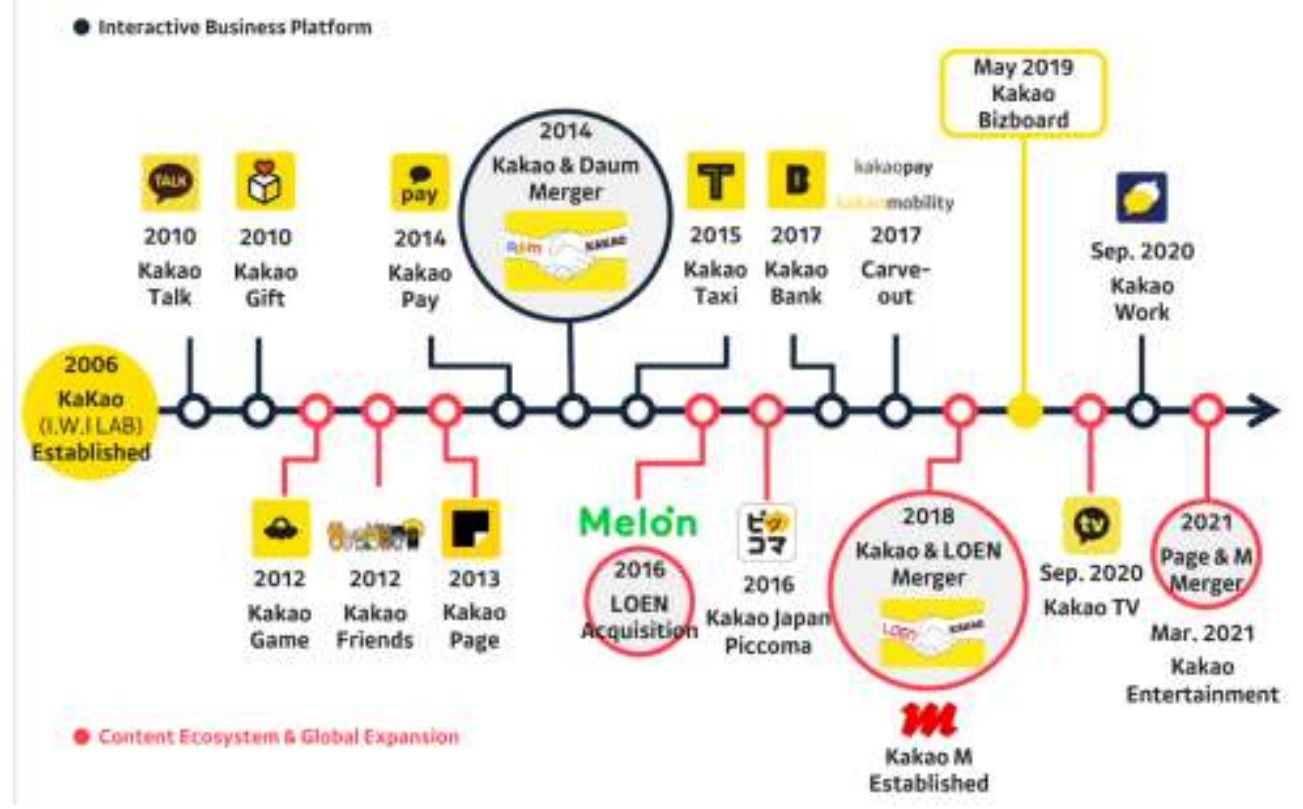

Fig. 4. Kakao's Business areas

Source: Kakao. Kakao Investor Relations. Feb. (2021)

Based on its brand power and popoularity, Kakao became the No. 1 company to work for, followed by many competent Korean companies.

Table 1. Best Korean companies to work for (2019/2020)

\begin{tabular}{|c|c|c|c|c|c|}
\hline Rank & 1 & 2 & 3 & 4 & 5 \\
\hline Company & kakao & SAMSUNG & NAVER & cJ enm & KGREANAIR \\
\hline Rank & 6 & 7 & 8 & 9 & 10 \\
\hline Company & (D) HYUחDAI & AMOREPACIFIC & 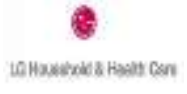 & & SK innovation \\
\hline
\end{tabular}

Source: S.B. Lee. Kakao selected as the best companies to work for. TV Chosun, Jul. 21 (2021) 


\section{Future of Kakao}

Kakao's stellar growth shows Korea's industry structure change from a manufacturing industry to an ICT service-based one. Few people expected that Kakao was able to be included in the top five list of the business conglomerates in terms of market capitalization. It successfully surpassed conventional global companies, such as LG, POSCO, Hyundai, and so on.

There existed several drives for this noticeable growth. First, its holding company, Kakao Corp's market value grew from \$28.9B (34 T Korean won) to \$53.6B (63 T Korean won). Second, the market value of the major subsidiaries, such as, Kakao Games, increased $228.12 \%$, from $\$ 1.4 \mathrm{~B}$ (1.7T Korean won) to $\$ 4.9 \mathrm{~B}$ (5.8T Korean won). Third, KakaoBank was valued at $\$ 15.8 \mathrm{~B}$ (18.5 Korean won) on the basis of its IPO price, and the market capitalization increased to $\$ 35.3 \mathrm{~B}$ (41.5 T Korean won).

More affiliates, such as Kakao Pay Corp., a mobile-payment service, Kakao Mobility Corp., a transportation service, and Kakao Entertainment, a music and contents company are expected to grow as next-stage cash cow sources.

Kakao has strived to expand its service from a digital world to a physical service, which is dubbed as Online to Offline $(\mathrm{O} 2 \mathrm{O})$. A golf service could be a good example, which is implemented by Kakao VX, Kakao Games's subsidiary.

The next focus is the culture and entertainment, which could be propelled by one of its affiliates, Kakao Entertainment. This company was formed through the merger of a music streaming service platform, Kakao M, and a content providing company, Kakao Page. Kakao Entertainment acquired a 100\% stake of Antenna Music, a pioneering indie music label in Korea, and through the negotiation process with Soo-Man Lee, who is one of trailblazers in the modernization of Korean music production industry.

Webtoons are another major pillar in Kakao's entertainment business. It recently acquired Japan's webtoon platform, Piccoma, with $\$ 600 \mathrm{M}$ (708B Korean won). In Japan, Kakao is trying to possess additional intellectual property (IP) rights, which will be one of revenue sources for the entire business group. With these efforts, Kakao's global market size has been steadily increasing as shown in Figure 5.

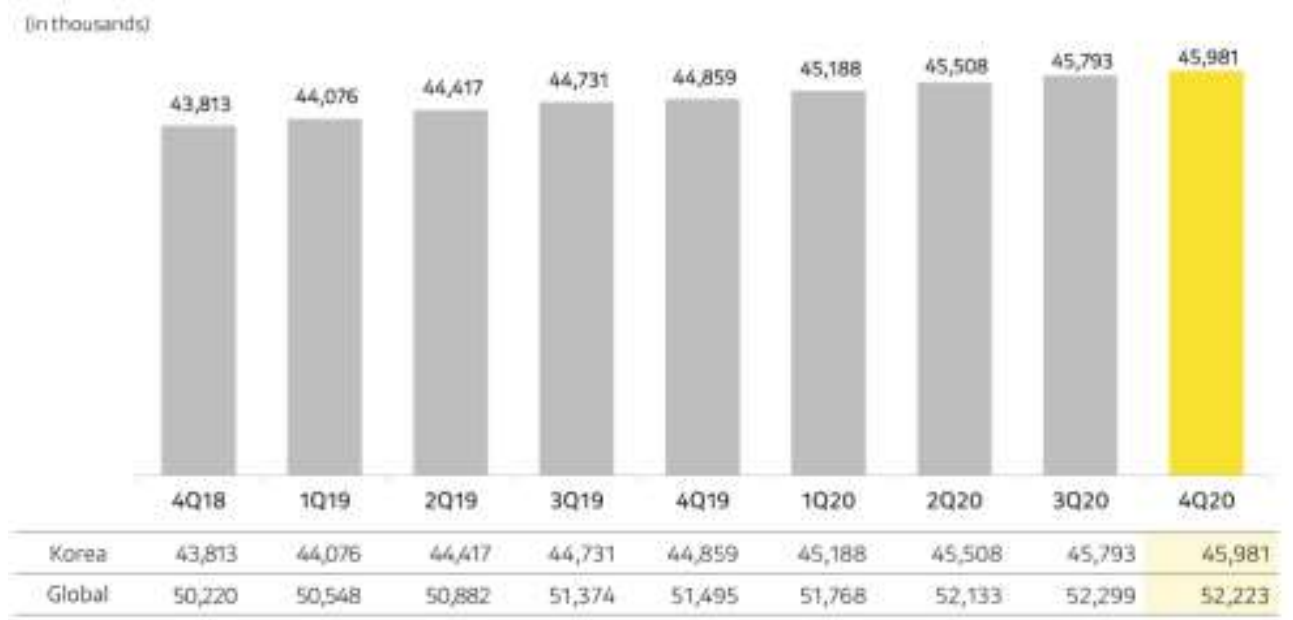

Fig. 5. Kakao's Domestic/Global Market Size

Source: Kakao. Kakao Investor Relations. Feb. (2021)

\section{Concluding Remarks}


Many reasons exist for this success. First, the Korean market has a larger share of the national economy in ICT than in other industries. ICT accounts for roughly $10 \%$ of the total value added generation, ranking first among OECD countries[14]. In addition, 4.7\% of all employment is in ICT, ranking first among OECD countries[15]. Such a well-established environment related to ICT played a major role in Kakao's development of mobile technology and its rapid commercialization. Given that there exist large and small ICT service providers, including smartphone developers, such as Samsung Electronics and LG Electronics, and games, such as Netmarble, NCsoft, and Nexon, they were able to quickly procure skilled ICT personnel and catch up with WhatsApp, which launched mobile messengers. In addition, when the Internet revolution broke out 20 years ago, a company called Naver survived fierce competition in the browser and portal industries. Given that most of Kakao's founders and early members are from Naver, the presence of people with a sense of and skills in existing ICT services has contributed to this. Although Google dominated the search engine market in most countries with its advent, Naver remains influential in Korea. Moreover, Koreans are the top users of mobile apps compared with major countries. With the increasing amount of mobile app users through platforms, such as Kakao Talk, the use of tools to communicate with one another has also increased.

Second, in terms of growth, "Playing Kakao Games" played a significant role, which utilized an advantageous position in Korea, the fourth largest game market in the world.

Third, many messenger developers, including Daum's My People and Naver's Line, delayed the release period and gave Kakao Talk time to promote. In addition, although mobile carriers, such as SKT or KT levied 10 to 20 Korean won per use, KakaoTalk offered the platform for free. In this period, WhatsApp maintained a pay-per-use policy until it was acquired by Facebook. In addition, although Line expanded to Japan and Southeast Asia, Kakao would have been able to compete in the Korean market. It launched Kakao Plain and Brucch services, which epitomized the "snack" culture. Its archrival Naver blocked advertising posts and provided UX, which is ideal for writing. However, it secured a quality blogger with a system that supports writers with good ideas and skills.

Fourth, the founder, Kim Bum-soo, made use of the experience he acquired in his previous workplace, i.e., Naver. After gaining a user base, Kakao provided expanded services, which is highly similar to NHN's growth strategy. Next, the company read the growth pattern of the global mobile messenger market and released it in the domestic market quickly. One "fast follower" strategy worked effectively. Subsequently, the company succeeded in attracting investments from outside and platforming them while risking deficits. On the basis of the platform, various services, such as banking, transportation, music, content, commerce, and so on are provided through active M\&A [16-20].

Finally, Kakao is strictly targeting Korean consumers. The service has been launched although it has been criticized due to its classic "copycat business." Although well-known conglomerates, such as, Samsung Electronics and Hyundai Motor, focus on overseas markets, most ICT companies in Korea are considered to have a "copy cat business." The company is bound to be underrated in terms of its performance. Nonetheless, Kakao quickly adopts new technologies, such as blockchain to the domestic market. Ultimately, Kakao is considered a leader owing to its ability to create a business model that has succeeded in gaining control of the market while ranking first in the global market.

\section{References}

1. K. Boudreau, Open platform strategies and innovation: Granting access vs devolving control. Management Science, 56(10), 1849-1872 (2010)

2. K.J. Boudreau, L.B. Jappesen, Unpaid crowd complementors: the platform network 
effect mirage. Strategic Management Journal, 36(12), 1761-177 (2015)

3. A. Chakravarty, A. Kumar, R. Grewal, Customer orientation structure for Internetbased business-to-business platform firms. Journal of Marketing, 78(5), 1-23 (2014)

4. M. de Reuver, C. Sørensen, R.C. Basole, The digital platform: A research agenda. Journal of Information Technology, 33(2), 124- 135 (2018)

5. J.T. Eckhardt, M.P. Ciuchta, M. Carpenter, Open innovation, information, and entrepreneurship within platform ecosystems. Strategic Entrepreneurship Journal, 12(3), 369-391(2018)

6. J. Han, O. Cho, Platform business eco-model evolution : Case study on Kakao Talk in Korea. Journal of Open Innovation: Technology, Market, and Complexity, 1(6), 1-14 (2015)

7. T. Eisenmann, G. Parker, M.W. van Alstyne, Platform envelopment. Strategic Management Journal, 32(12), 1270-1285 (2011)

8. J.A. Fehrer, H. Woratscheck, R.J. Brodie, A systemic logic for platform business model, Journal of Service Management, 29(4), 546-568 (2018)

9. D.S. Evans, R. Schmalensee, Failure to launch: Critical mass in platform businesses, Review of Network Economics, 9(4), 1-26 (2010)

10. G.G. Parker, M.W., van Alstyne, Innovation, openness, and platform control. Managment Science, 64(7), 3015-3022 (2018)

11. R. Perren, R.V. Kozinets, Lateral exchange markets: How social platforms operate in a networked economy. Journal of Marketing, 82(1), 20-36 (2018)

12. K. Rong, Y. Lin, Y. Shi, J. Yu. Linking business ecosystem lifecycle with platform strategy: A triple view of technology, application and organisation. International Journal of Technology Management, 62(1), 75-94 (2013)

13. K. Täuscher, S.M. Laudien, Understanding platform business models: A mixed methods study of marketplaces. European Management Journal, 36(3), 319- 329 (2018)

14. OECD. Employment in the ICT Sector and Sub-sectors, 2015 (2017a)

15. OECD. Value added of the ICT Sector and Sub-sectors, 2015 (2017b)

16. A. Hatiu, E.J. Altman, Finding the platform in your product: Four strategies that can reveal hidden value, Harvard Business Review, 95(4), 94-100 (2017)

17. J. Oh, B. Koh, S. Raghunathan, Value appropriation between the platform provider and app developers in mobile platform mediated networks, Journal of Information Technology, 30(3), 245-259 (2015)

18. Y. Zhao, S., Delft, A. Morgan-Thomas, T. Buck, The evolution of platform business models: Exploring competitive battles in the world of platforms. Long Range Planning, 53(4), 1-24 (2020)

19. F. Zhu, M. Iansiti, Entry into platform-based markets. Strategtic Management Journal, 33(1), 88-106 (2012)

20. F. Zhu, M. Iansiti, Why some platforms thrive and others don't. Havard Business Review, 97(1), 118-125 (2019) 